\title{
PRINCIPAIS PROBLEMAS FISIOLÓGICOS APRESENTADOS POR PACIENTES COM INFARTO DO MIOCÁRDIO E AS RESPECTIVAS PRESCRIÇÕES DE ENFERMAGEM
}

\author{
Moema Guedes Barbato * \\ Kiyomi Uechi ** \\ Neusa Akemi Watakabe** \\ Suely Hayashi**
}

BARBATO, M. G.; UECHI, K.; WATAKABE, N. A.; HAYASHI, S. Principais problemas fisiológicos apresentados por pacientes com infarto do miocárdio e as respectivas prescrições de enfermagem. Rev. Esc. Enf., São Paulo, 13(2): 147-155, 1979.

As autoras descrevem problemas relativos a dor, equilibrio circulatório, freqüência cardíaca, equilíbrio enzimático e eletrolitico, termo-regulação, sono, repouso, eliminação, terapêutica $e$ nutrição em pacientes com infarto do miocárdio. Em seguida indicam quais seriam as prescriçôes de enfermagem a serem adotadas, pelo pessoal de enfermagem, frente a tais problemas.

\section{INTRODUÇÃO}

A idéia deste trabalho nasceu da constante necessidade que têm as enfermeiras em orientar os profissionais de enfermagem que ingressam nas unidades coronarianas, sobre quais os principais problemas bio-psico-sócio-espirituais que acometem os pacientes coronariopatas e conseqüentemente a prescrição de enfermagem.

Neste trabalho as autoras se detém apenas nos aspectos biológicos, reservando para outra oportunidade a abordagem das demais áreas.

As autoras buscaram, de maneira simples e sintética, descrever os problemas mais comuns identificados nos coronariopatas e possibilitar, o pessoal de enfermagem, recordar a assistência de enfermagem que deve ser dada a esses pacientes .

\section{PROBLEMAS}

Os problemas serão citados sem nenhuma pretensão em hierarquizá-los. DOR (PERCEPÇÃO DOLOROSA).

Característica da dor: duradoura, do tipo opressivo, na região retro esternal, que irradia para os braços, pescoço, mandibula ou omoplata e às vezes para a região epigástrica. Normalmente é acompanhada de sudorese, vômitos, diarréia, lipotímia, ansiedade, bradicardia ou taquicardia.

\section{Prescrição de enfermagem:}

- solicitar ao paciente que verbalize e caracterize o tipo da dor;

- orientar o paciente para permanecer em repouso; deixá-lo confortável;

* Docente Livre de Enfermagem Médico-Cirúrgica pela Escola Ana Neri da Universidade Federal do Rio de Janeiro. Professor Assistente da disciplina Enfermagem Médico-Cirúrgica 11 da EEUSP.

* Aluna de Habilitação em Enfermagem Médico-Cirúrgica II da EEUSP. 
- observar as condiçóes bio-psicológicas do paciente;

- sedar segundo a prescrição médica;

- comunicar ao médico se a dor não ceder:

- colocar catéter de oxigênio, se indicado.

\section{EQUILIBRIO CIRCULATÓRIO}

Pressão arterial:

- hipertensão

- má perfusão periférica

- hipotensão

Na fase inicial do infarto do miocárdio a pressão arterial costuma estar normal ou pouco elevada, a não ser nas formas inicialmente graves que podem ser acompanhadas do estado de choque. Dentro de horas ou de poucos dias, dá-se uma queda tensional gradativa. Esta hipotensão costuma persistir por dias ou semanas.

Prescrição de enfermagem:

- controlar a pressão arterial de $4 / 4$ horas e sempre que necessário;

- verificar a pressão arterial em ambos os braços e, se houver diferença significativa, verificar sempre onde se encontram as cifras superiores;

— verificar a perfusão dos membros inferiores;

- correlacionar a pressão arterial com a medicação;

- orientar o paciente para não fazer movimentos bruscos, por exemplo, na mudança de decúbito.

\section{FREQÚENCIA CARDIACA}

Taquicardia

Seu aparecimento está relacionado com a sensibilidade do paciente sob forma de taquicardias acentuadas, extra-sístoles, fibrilação auricular ou outros distúrbios de ritmo, principalmente, as taquicardias ventriculares.

Bradicardia

Pode ocorrer espontaneamente ou ser ocasionada por sedativos ou por transtornos da condução atrioventricular.

Prescrição de enfermagem:

- monitorização constante;

- observar o traçado eletrocardiográfico; 
- controlar o pulso e a freqüência cardíaca de $4 / 4$ ou $6 / 6$ horas e quando necessário;

- medicar conforme a prescrição médica;

- deixar o carro de emergência sempre equipado e próximo ao paciente ou da unidade.

Monitorização

Monitorização permanente do paciente propicia terapêutica profilática, evitando maiores complicações. A colocação exata dos elétrodos varia segundo as diferentes equipes clínicas; o seu objetivo é controlar a freqüência cardaica e o aparecimento de disritmias.

Prescrição de enfermagem:

- explicar ao paciente a necessidade da monitorização como um fator de segurança;

- orientar sobre a mudança de decúbito, devido aos fios dos elétrodos;

- colocar o limite de alarme em níveis adequados; ao alarme, observar o traçado eletrocardiográfico e as condições dos elétrodos e aparelho;

- manter durante o banho no leito a monitorização, evitando molhar os elétrodos. Adaptar a técnica do banho;

- dizer ao paciente da possibilidade de mobilização;

- observar freqüência cardíaca e disritmias constantemente.

\section{EQUILIBIO ENZIMÁTICO E ELETROLÍTICO}

\section{Enzimas}

Em presença de infarto agudo do miocárdio as enzimas se libertam das células e passam para o sangue. Este fato é utilizado para fins diagnósticos junto com ECG. Os enzimas mais pesquisados, atualmente, são: TGP; TGO; CPK; DHL. (Anexo I e II.)

\section{Eletrólitos}

As modificações dos vários eletrólitos contidos no plasma (principalmente o potássio) influenciam o ritmo e a freqüência cardíaca, bem como a atividade dos marca-passos.

Prescrição de enfermagem:

- orientar o paciente quanto à necessidade da colheita de sangue;

- puncionar uma veia periférica e mantê-la permeável;

- colher sangue de $4 / 4$ horas, nas primeiras 24 horas (enzimas e eletrólitos). Acompanhar os resultados; 
- administrar soros polarizantes ou balanceados ,correlacionando com os resultados dos exames laboratoriais $(\mathrm{K})$ e o traçado eletrocardiográfico;

- oferecer suco de laranja.

\section{TERMO REGULAÇÃO}

Hipertermia

No infarto, há uma liberação de substâncias quimicas ao nível do miocárdio. A sua absorção desenvolve a hipetermia .Eleva-se nas 24 a 72 horas após o infarto. Se a temperatura se mantiver elevada após esse período deve ser pesquisada a etiologia.

Prescrição de enfermagem:

- controlar a temperatura de $4 / 4$ horas ou quando necessário;

- medicar segundo a prescrição médica;

- verificar a sudorese após a medicação e trocar a roupa de cama;

— oferecer líquidos.

\section{REPOUSO E SONO}

- repouso absoluto

- ansiedade

- insônia

A atividade física e a atividade mental devem reduzir-se a um mínimo por um período que permita a cicatrização da área lesada do coração. Deve-se evitar a sobrecarga cardíaca.

Prescrição de enfermagem:

observar e orientar o paciente sobre:

- repouso absoluto (posição de Fowler, se necessário);

- movimentação passiva dos membros inferiores para prevenir flebotromboses e conseqüente embolia pulmonar;

- mudança de decúbito - melhora a ventilação pulmonar e previne escaras;

- medicar com tranqüilizantes e/ou hipnóticos em horários apropriados segundo prescrição médica;

- proporcionar ambiente adequado e confortável ao paciente.

\section{ELIMINAÇÃO}

Obstipação intestinal

É muito freqüente, resultante do repouso no leito e dos opiáceos. As eliminações constituem um problema devido a dificuldade da maioria dos pacientes em usar a comadre no leito. 
Prescrição de enfermagem:

- observar se o paciente apresenta obstipação há mais de 3 dias, comunicar ao médico e medicá-lo;

- oferecer dieta não obstipante e líquidos;

- estimular mudança de decúbito (movimentação passiva e ativa no leito);

- observar e anotar o efeito da medicação e as características das fezes;

- acompanhar o paciente ao banheiro, caso já esteja deambulando;

- orientar para que não faça muito esforço.

Náuseas e vômitos

Possivelmente é devido a reflexos vagovagais originários na zona de infarto e refletidos no trato digestivo.

Prescrição de enfermagem:

- administrar antiemético prescrito;

- assistir o paciente durante as crises de vômito;

- observar as caracteristicas do vômito e anotar;

- orientar quanto à posição da cabeça.

\section{TERAPEUTICA}

- dor precordial

- vaso constricção

- ansiedade

- trombose

- disritmias

Orientar o paciente quanto à importância e ação dos medicamentos e efeitos colaterais. São eles:

Vaso dilatadores: medicar quando o paciente apresentar precordialgia. Efeitos colaterais: hipotensão, cefaléia, náuseas e vômitos. Avisar o médico se os sintomas persistirem.

Beta bloqueadores: fazer controle de pulso e freqüência cardiaca antes de administrá-lo. Contra-indicação: bradicardia, hipotensão, choque e insuficiência cardíaca congestiva.

Antidistônicos, sedativos, hipnólicos: proporcionar repouso e evitar estresse. Observar: sonolência, torpor, confusão mental e arritmias.

Analgésicos: medicar quando o paciente apresentar dor. Efeitos colaterais: vômito, náusea, tontura, bradicardia. Contra-indicação: portadores de doença respiratória.

Antiarrítmicos: indicados nas extrassístoles e taquicardia supraventriculares e extrassístoles ventriculares. Observar efeitos através dos monitores ou do ECG.

$\mathrm{Na}$ bradicardia observar os efeitos da mesma maneira acima. 


\section{NUTRIÇÃO}

Nas 12 horas após o infarto, deixar o paciente em jejum para evitar aspiração de vômito e conseqüente complicações pulmonares. A dieta deve ser líquida, branda ou pastosa, de acordo com a prescrição médica.

\section{Prescrição de enfermagem:}

- comunicar à nutricionista o tipo de dieta;

— dar alimentação na boca do pacietne se ele não tiver condições de alimentar-se sozinho;

- verificar a aceitação da dieta e comunicar à nutricionista. Estimular a alimentação.

- evitar alimentos muito quente ou muito frio (pode desencadear disritmias);

— controlar e anotar a ingestão hídrica e líquidos eliminados (urina nas 24 horas - diurese).

BARBATO, M. G.; UECHI, K.; WATAKABE, N. A.; HAYASHI, S. Main physiological problems presented by patients with respective nursing prescription. Rev. Esc. Enf. USP, São Paulo, 13(2): 147-155, 1979.

In this paper, the authors relate the main physiological problems identified by nurses in myocardial infarction patients. Following, they present which were the nursing prescriptions to be adopted by nursing personnel, facing such problems.

\section{BIBLIOGRAFIA}

BARBATO, M. G. - Estudo crítico das alterações dos sinais vitais e eletrocardiográficas, secundárias ao banho no leito, em portadores de insuficiência coronariana aguda. São Paulo, 1977. (Tese de Livre Docência - Escola de Enfermagem Ana Neri).

BERTOLASI, C. A. \& TRONGE, J. E. - Unidad coronaria. Buenos Aires, Intermédica, 1972. 220 p.

BRAMS, W. A. - Vença o enfarte. São Paulo, Institulçăo Brasileira de Difusão Cultural, 1967.115 p.

BRUNNER, L. S. \& SUDDARTH, D. S. - Enfermagem médico cirúrgica. 3. ed. Rio de Janeiro, Intera. mericana, $1977.1269 \mathrm{p}$.

CHAPARRO, E. - Terapia intensiva y unidad coronaria. Argentina, Panamericana, 1973. 136 p.

DECCACHE, W. - Arritmias cardiacas. Rio de Janeiro, Atheneu, 1971.

DUTRA, W. de O. coord. - Enfermagem em cardiologia: procedimentos. São Paulo, Hospital das Clínicas, Instituto do Coração, 1976. $231 \mathrm{p}$.

GOODMAN, L. S. \& GILMAN, A. - As bases farmacológicas da terapêutica. 4. ed. Rio de Janeiro, Guanabara Koogan, 1973. 1615 p.

MACBRYDE, A. B. \& BLACKLOW, A. B. - Sinais e sintomas. 5. ed. Rio de Janeiro, Guanabara Koogan, 1975. $941 \mathrm{p}$.

MACRUZ, R. - A dor cardiaca. São Paulo, Sarvier, 1976. 185 p.

MELTZER, L. E. et alii - Guidados intensivos para el paciente coronariano. 2. ed. México, La Prensa Médica Mexicana, 1973.

MILLER, O. et alii - Laboratório para o clínico. 3. ed. Rio de Janeiro, Atheneu, 1977.693 p.

MODELL, M. D. - Manual de cardiologia para enfermeras. México, La Prensa Médica Mexicana, 1969.

MUNIZ, M. de F. - Cardiologia de urgência. Guanabara, Muniz, 1967. v. 1.

SECOR, J. - Coronary care: a nursing speciality. New York, Appleton Century Crofts, $1972.167 \mathrm{p}$.

SMITH, D. W. et alii - Enfermería medico quirúrgica. 3. ed. México, Interamericana, 1973.1105 p.

YOKES, J. A. - The clinical specialist in cardiovascular nursing. Amer. J. Nurs., New York, 66 (12): 2667-70, Dec. 1966. 


\section{ANEXO I}

\section{ENZIMA}

$T G O$ - Transaminase glutâmica oxalacética.

Encontra-se em alta concentração no miocárdio normal e se eleva no sangue em caso de necrose miocárdica. $O$ aumento começa depois de 12 horas e se mantém por 3 a 5 dias. $O$ nível parece guardar certa relação com a extensão do infarto, sendo útil fazer determinações seriadas por alguns dias para observar a evolução dos resultados até a sua normalização.

A TGO pode estar elevada em outros estados patológicos como choque, hepatopatias, cirurgia cardíaca, etc., mas complementado este dado com a clínica e o ECG pode-se chegar a um diagnóstico seguro.

TGP - Transaminase glutâmica pirúvica.

É amplamente distribuída nos tecidos, com predominância no fígado, rim e coração.

Embora tenha maior campo de aplicação nas doenças do fígado, pois a necrose hepática determina grande elevação de seus níveis sanguíneos, a TGP sanguínea também pode alterar-se nos infartos do miocárdio, fato que sucede em aproximadamente $55 \%$ dos casos desta enfermidade.

Seu valor normal é de 3 a $25 \mathrm{U} / \mathrm{ml}$. Nos infartos pequenos ela se encontra dentro dos limites da normalidade, mas a medida que a zona de necrose se torna mais extensa, seus níveis sanguíneos também se alteram, tanto assim que nos infartos extensos, com niveis de TGO elevado a $150 \mathrm{U}$ não raramente os níveis de TGP se encontram elevados.

DHL — Desidrogenase lática.

Encontra-se em diversos tecidos do organismo e aparece no sangue depois de lesão de tecidos.

No infarto agudo do miocárdio (IAM) o valor aumenta logo nas primeiras 12 a 24 horas, atinge o máximo entre o $20^{\circ}$ e $4 .^{\circ}$ dia de evolução e gradualmente declina ao seu valor normal entre 8 e 14 dias.

A enizma pode elevar-se nos casos de infarto de pulmão, necrose renal, câncer, etc.

\section{$C P K$ - Creatino-fosfoquinase.}

Encontra-se em grande quantidade nos músculos cardíaco e esquelético. O nível se eleva com rapidez no caso de IAM ou de lesão muscular. 
Não aumenta nas enfermidades renais, hepáticas ou hematológicas. Os valores de CPK são privativos de IAM.

Os níveis de CPK já exibem alteração 3 a 4 horas após o início da dor, o que torna essa enzima particularmente útil para avaliar o grau de necrose miocárdica nessa fase precoce. Sua normalização ocorre em torno do terceiro dia.

Observação:

A injeção intramuscular de derivado diazº́nico pode causar liberação local de CPK, com repercussão sobre o seu nível séricon. Tal fato exibe interesse clínico, de vez que o citado medicamento está presente com freqüência em pacientes com infarto do miocárdio, o que pode provocar falsos resultados na dosagem dessa enzima. 


\section{ANEXO II}

EPOCAS CRONOLOGICAS DAS ALTERAÇOES

\begin{tabular}{|c|c|c|c|c|}
\hline Exames laboratoriais & $\begin{array}{l}\text { Normal } \\
\text { máximo }\end{array}$ & $\begin{array}{l}\text { Início das } \\
\text { alteraçōes }\end{array}$ & $\begin{array}{l}\text { Alterações } \\
\text { máximas }\end{array}$ & $\begin{array}{c}\text { Volta ao } \\
\text { normal }\end{array}$ \\
\hline Hemossedimentação & $10 \mathrm{~mm} / 1 .^{\mathrm{a}}$ hora & $2 .^{\circ}$ ou $3 .^{\circ}$ dia & $5 .^{\circ}$ dia & $30-60$ dias \\
\hline Mucoproteínas & $4 \mathrm{mg} \%$ & $2 .^{\circ}$ ou $4 .^{\circ}$ dia & $4 .^{\circ}$ dia & $30-60$ días \\
\hline Leucocitose & 8.000 & $1 .^{\circ}$ ou $2 .^{\circ}$ dia & 7.० dia & 10 dias \\
\hline Proteína C Reativa & negativo & 1..$^{\circ}$ ou $2 .^{\circ}$ dia & $4 .^{\circ}$ dia & $1 / 2$ semanas \\
\hline TGO & $5 / 40$ unidades & 6 a 12 horas & $36 / 48$ horas & 5 dias \\
\hline CPK & $\begin{array}{l}\text { de acordo com } \\
\text { o método }\end{array}$ & 6 a 12 horas & $12 / 36$ horas & 3 dias \\
\hline DHL & $200 / 430 \mathrm{U}$ & 6 a 12 horas & $30 / 40$ horas & $7 / 12$ dias \\
\hline TGP & 25 a $35 \mathrm{U}$ & & & \\
\hline
\end{tabular}

